\title{
Seletividade na cominuição de mesclas de dolomita e quartzo
}

\author{
Selective comminution of dolomite and quartz mixtures
}

\section{Germano Mendes Rosa \\ Instituto Federal Minas Gerais \\ IFMG - Campus Congonhas \\ Coordenadoria de Produção Industrial \\ e Mineração \\ Mestrado pelo PPGEM/UFOP \\ E-mail: germano_rosa@yahoo.com.br}

\section{José Aurélio Medeiros da \\ Luz \\ Universidade Federal de Ouro Preto \\ Escola de Minas, Departamento de Engenharia de Minas - DEMIN/UFOP \\ E-mail: jaurelio@demin.ufop.br}

\section{Resumo}

Esse artigo dá prosseguimento à pesquisa que deu origem a artigo anterior, apresentando resultados referentes à seletividade da moagem de mesclas dos minerais dolomita e quartzo sob diferentes proporções. Apresenta-se, aqui, o indicador global de contraste granulométrico (IGCG), utilizado para dar suporte à análise do comportamento granular das espécies minerais no produto, a partir das respectivas curvas de distribuições das frações retidas simples, regredidas das nuvens de pontos das análises granulométricas por meio da função de distribuição de probabilidades sigmoidal de Hill. Os resultados indicaram o tempo ótimo de moagem, na amplitude de moagem considerada. Os resultados subsidiaram, também, o desenvolvimento de sistema simulador de cominuição baseado em rede neural artificial (do tipo perceptron de multicamada com algoritmo de supervisão e treinamento por retropropagação com momento), a ser objeto de artigo futuro.

Palavras-chave: Cominuição seletiva, mesclas binárias, contraste granulométrico, moagem, rede neural artificial.

\section{Abstract}

This article is a sequence of another one and displays results in the selective comminution of binary mineral mixtures. The selectivity of dolomite and quartz grinding rates under different proportions was studied. The called global grain contrast indicator (IGCG) was used to improve the analyses of the behavior of these minerals under comminution, using theoretical size distribution curves, fitted to the Hill's sigmoidal function. The results have suggested the optimum grinding times, within the tested range. The results presented here have validated the development of a neural network-based predictive model for grinding system simulation (a multilayer perceptron using backward propagation with moment), which will be approached in another article.

Keywords: Selective comminution, binary mix, grinding, artificial neural network. 


\section{Introdução}

$\mathrm{O}$ alto custo do processo de moagem, principalmente na faixa de granulação fina, é muito citado. A razão de redução (razão entre o diâmetro da alimentação e do produto) é, relativamente, pequena em cada estágio de cominuição (Beraldo, 1987), por razões técnico-econômicas. Por isso, normalmente, utilizam-se diversas etapas ou estágios, nesse processo, para se atingir uma redução significativa do tamanho do sólido, lançando mão da utilização de vários equipamentos trabalhando em série, em regime de circuito aberto, fechado ou misto.

Cabe ressaltar que a intensidade de cominuição aplicada a determinado sólido pode ser definida por meio de uma função de cunho econômico, onde se avaliam os custos do processo de moagem, a taxa de produção, bem como seus impactos nos processos subsequentes, em termos de recuperação e grau de enriquecimento do componente útil (quando for o caso).

Para efeito de comparação de consumo energético entre operações mineiras, pode-se apoiar nas informações contidas na Tabela 1.

Observa-se que, na operação de moagem, o consumo energético pode variar de 10 a 100 vezes o que se gasta na operação precedente, a britagem.

Portanto torna-se preponderante o conhecimento da evolução do contraste granulométrico das espécies minerais componentes de um determinado minério, a partir das características de alimentação e parâmetros de operação, a fim de se obter maior aproveitamento energético no processo de moagem e, paralelamente, se conseguirem melhorias na seletividade das operações separatórias a jusante, na rota de processo. Nesse sentido, trabalhos anteriores têm enfatizado a conveniência da seletividade na cominuição de mesclas binárias, como, por exemplo, Rosa (2009), Rosa e Luz (2009) e Sudário e Luz (2009).

\section{Materiais e métodos}

Fez-se uso das informações apresentadas no artigo anterior (Rosa e Luz, 2009), no desenvolvimento do presente trabalho. Uma das principais informações que se avaliou se relaciona à hipótese levantada naquele artigo de que o ciclo ótimo de cominuição, para cada proporção de mescla, corresponderia ao instante determinado pela interseção dos coeficientes de agudez dos minerais nos seus respectivos produtos.

Para operacionalizar a comparação granulométrica das espécies minerais, definiu-se o que foi chamado de indicador global de contraste granulométrico (IGCG), que tem a seguinte expressão:

$I G C G=0,5 \cdot \sum_{i=1}^{n}\left|x_{1 i}-x_{2 i}\right|$
Onde:

$x_{1 i}$ : fração retida simples do mineral da espécie 1 na faixa granulométrica $i[-]$.

$x_{2 i}$ : fração retida simples do mineral da espécie 2 na faixa granulométrica $i[-]$.

|.|: função-módulo.

n: número de faixas granulométricas.

O valor do IGCG se localiza no intervalo $[0,1]$ e seu significado físico equivale à fração das áreas sob as curvas granulométricas (retido simples) das espécies minerais que não se interseccionam, o que se convencionou chamar aqui de contraste granulométrico.

A identificação dos produtos dos diversos ensaios de moagem foi estabelecida segundo critério de nomenclatura que leva em conta a proporção dos minerais na mistura e o respectivo tempo de moagem. Tal critério seguiu o padrão apresentado na Figura 1.

Para efeito de exemplificação, uma mistura composta por $25 \%$ em volume do mineral dolomita e $75 \%$ em volume do mineral quartzo, submetida a um ciclo de moagem de 5 minutos, seria assim escrita: T25D/75Q-5.

O teor de dolomita, em cada fração granulométrica individualizada, foi obtido por calcinação a $900^{\circ} \mathrm{C}$, já que a perda de massa da amostra previamente seca será devida à evolução de dióxido de carbono, visto que o quartzo permanece estequiometricamente inalterado (detalhes podem ser vistos em Rosa e Luz, 2009).

Tabela 1 - Consumo energético de algumas operações mineiras (Adaptado de Delboni Junior, 2007, p. 107).

\begin{tabular}{c|c}
\hline Operação Mineira & Consumo (kJ/kg) \\
\hline Desmonte de rochas & 0,36 \\
\hline Britagem & 3,6 \\
\hline Moagem & $36-360^{*}$ \\
\hline
\end{tabular}

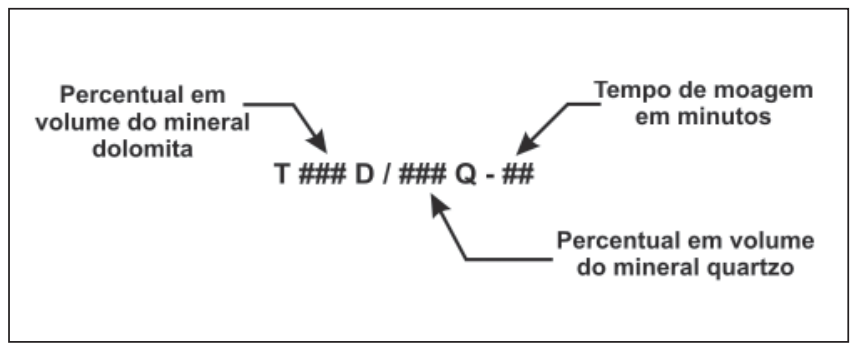

Figura 1 - Padrão de nomenclatura utilizado para identificação dos diversos produtos das moagens físicas das misturas. 
As curvas das frações retidas simples dos produtos das mesclas foram obtidas por regressão da nuvem de pontos da distribuição do percentual passante acumulado das análises granulométricas das mesmas, sendo utilizada a função de distribuição de probabilidades sigmoidal de Hill.

As curvas das frações retidas simples correspondentes aos ciclos equivalentes aos instantes de interseção das curvas que representam os coeficientes de agudez dos produtos foram obtidas por determinação gráfica, via regressão não linear, dos parâmetros da função sigmoidal de Hill.

O programa computacional de análise estatística de dados gráficos utilizado foi o EasyPlot for Windows, versão
4.0.4, desenvolvido por S. Karon (www. spiralsoftware.com). Seu algoritmo usa filtro de Marquardt-Levenberg, o qual, ao contrário do algoritmo de busca por simplex descendente, permite a estimação das incertezas associadas aos valores de regressão (Luz, 2005).

\section{Resultados e discussão}

Inicialmente, registre-se que outras distribuições teóricas usuais foram testadas em fase inicial do trabalho, avaliando-se sua aderência estatística à nuvem de dados experimentais. Entre essas curvas estudadas, ressaltaram-se a clássica distribuição de Rosin-Rammler e a sigmoidal de Hill, com nível de aderência aproximado. A sigmoidal de Hill foi adotada por sua maior simplicidade algébrica e se revelou satisfatória como descritora da granulometria das amostras.

O tempo ótimo de moagem foi determinado para cada mescla dentro da amplitude de tempo de operação considerada, determinando-se, inclusive, as curvas para os instantes onde houve interseção das curvas representativas dos coeficientes de agudez para cada proporção de mescla. Os minerais apresentam IGCG da ordem de 0,20 na alimentação.

As Figuras 2, 3 e 4 mostram as diferentes distribuições das frações retidas simples na alimentação e nos produtos das moagens, segundo os ciclos de tempos considerados, construídas a partir
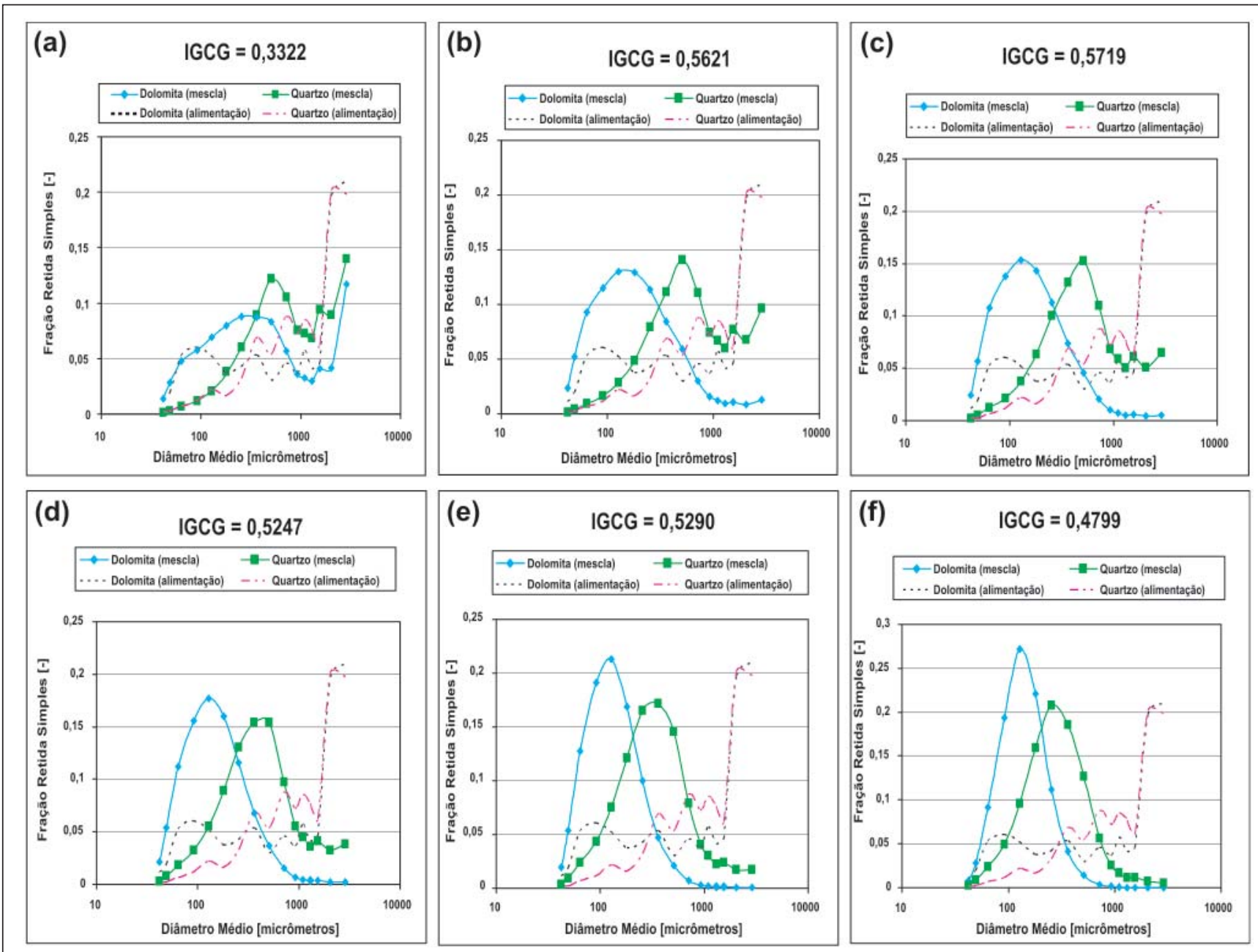

Figura 2 - Comparação das distribuições das frações retidas simples da mescla T25D/75Q para os ciclos de moagem de (a) 5 minutos, (b) 15 minutos, (c) 22 minutos, (d) 30 minutos, (e) 50 minutos e (f) 75 minutos. 


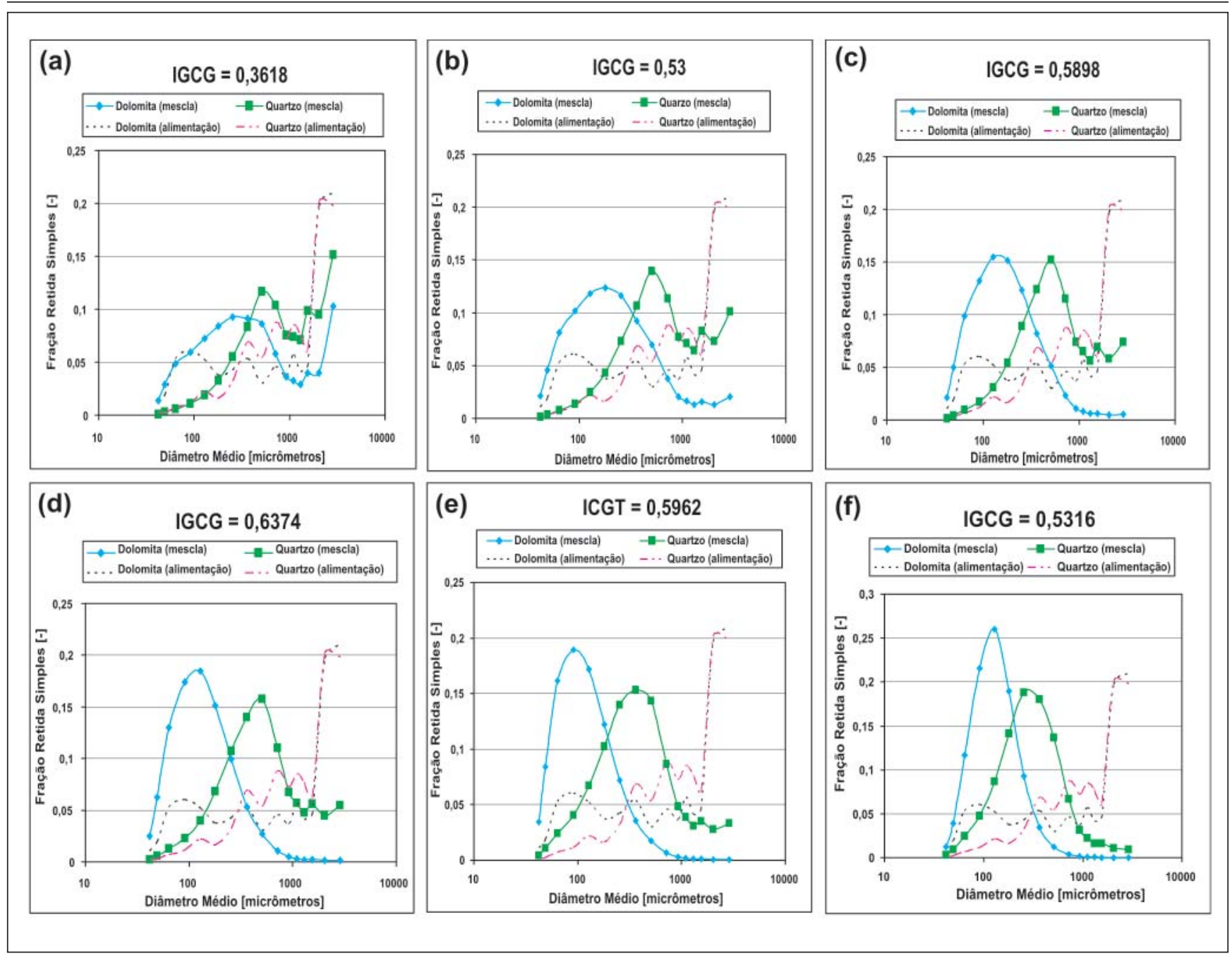

Figura 3 - Comparação das distribuições das frações retidas simples da mescla T50D/50Q para os ciclos de moagem de (a) 5 minutos, (b) 15 minutos, (c) 23 minutos, (d) 30 minutos, (e) 50 minutos e (f) 75 minutos.

dos parâmetros de ajuste das distribuições das frações passante acumulada, ajustadas para a função de distribuição de probabilidades de Hill, para os produtos das mesclas T25D/75Q, T50D/50Q e T75D/25Q. O IGCG foi calculado para cada proporção e se encontra destacado em cada gráfico.

A mescla T25D/75Q foi a única cujo tempo ótimo de moagem correspondeu ao instante determinado pela interseção das curvas representativas dos coeficientes de agudez dos produtos, cujo ciclo foi de 22 minutos, com um IGCG igual a 0,5719 , o que corresponde a um aumento de $86 \%$ no contraste granulométrico da alimentação.

Para os demais padrões, os tempos ótimos de moagem ocorreram em 30 e
75 minutos, respectivamente, para as mesclas T50D/50Q e T75D/25Q. Os valores de ICGC foram iguais a 0,6374 e 0,6235 , correspondendo a aumentos da ordem de $111 \%$ a $119 \%$, no contraste granulométrico da alimentação.

Portanto descarta-se a hipótese levantada de que o instante determinado pela interseção das curvas representativas dos coeficientes de agudez dos produtos equivaleria ao ciclo ótimo de moagem. Porém, para esses ciclos de moagem, verificaram-se valores de ICGC superiores a 0,57.

A evolução temporal do parâmetro IGCG, para as diversas proporções estudadas nesse trabalho, está apresentada na Figura 5.

\section{Conclusão}

O parâmetro IGCG se mostrou eficaz como estimador do contraste granulométrico. As análises mostraram que o ciclo ótimo de moagem para as mesclas consideradas não correspondeu, em todos os padrões, ao instante de interseção das curvas representativas dos coeficientes de agudez dos produtos. Porém, se considerado o fator econômico, tal hipótese pode ser válida, uma vez que os ciclos equivalentes a tais instantes corresponderam a valores suficientemente elevados de IGCG, não sendo muito inferiores aos valores ótimos globais, uma vez que correspondem a ciclos de moagem menores. 


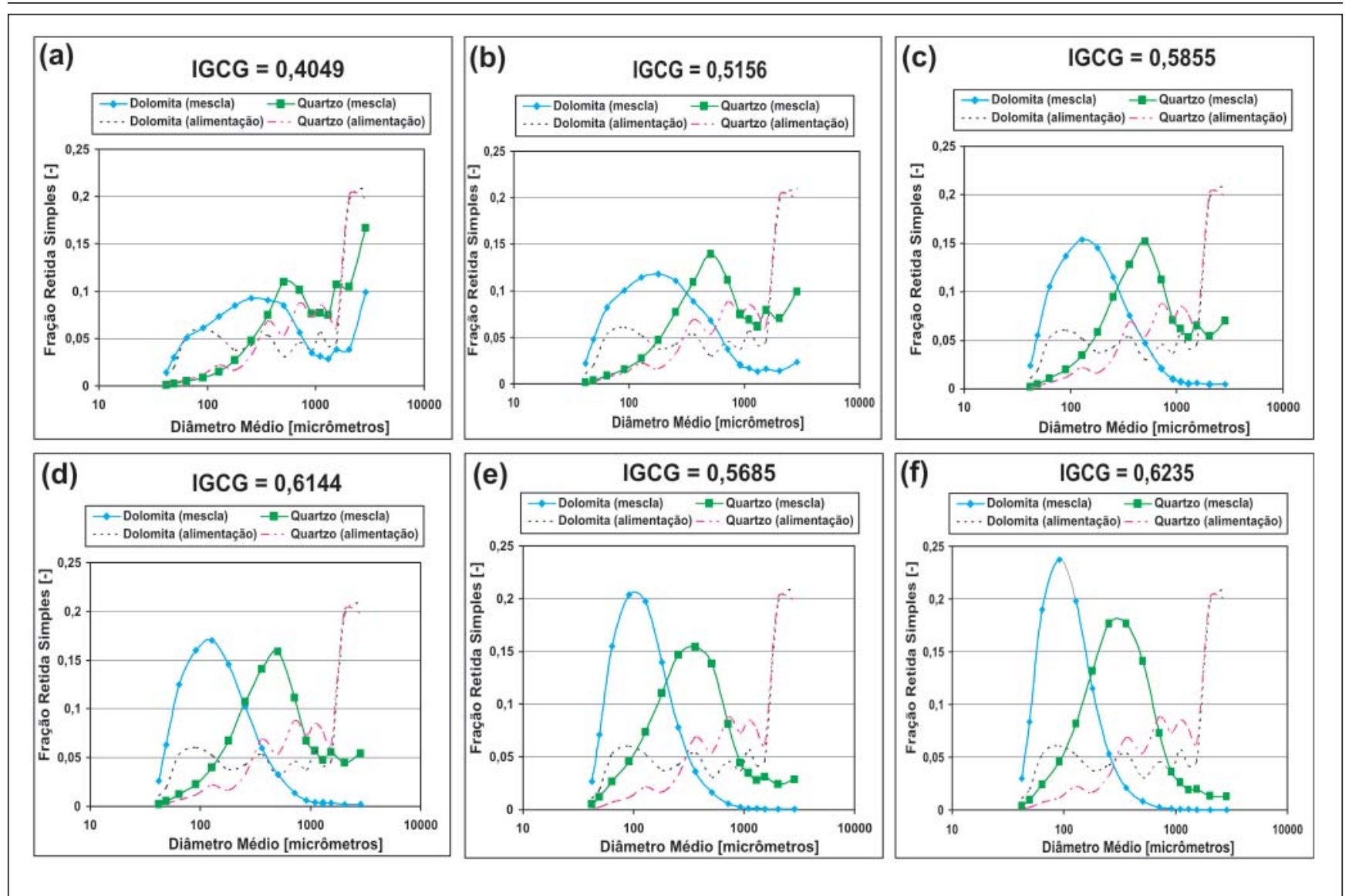

Figura 4 - Comparação das distribuições das frações retidas simples da mescla T75D/25Q para os ciclos de moagem de (a) 5 minutos, (b) 15 minutos, (c) 25 minutos, (d) 30 minutos, (e) 50 minutos e (f) 75 minutos.

A análise geral do comportamento do IGCG para as mesclas binárias estudadas leva à conclusão de que o IGCG se apresenta diretamente proporcional ao teor do mineral de maior moabilidade, nesse caso, a dolomita. Nesses termos, a proporção de mistura T75D/25Q apresentou, no geral, melhores IGCG.

A título de nota de encerramento, registre-se que a simulação do desempenho de misturas binárias via redes neurais artificiais foi realizada com sucesso, utilizando os dados gerados nesse trabalho. Tal sistema computacional será objeto de futuro artigo a ser submetido brevemente.

\section{Referências bibliográficas}

BERALDO, J. L. Moagem de minérios em moinhos tubulares. São Paulo: Edgard Blücher, 1987. 143 p.

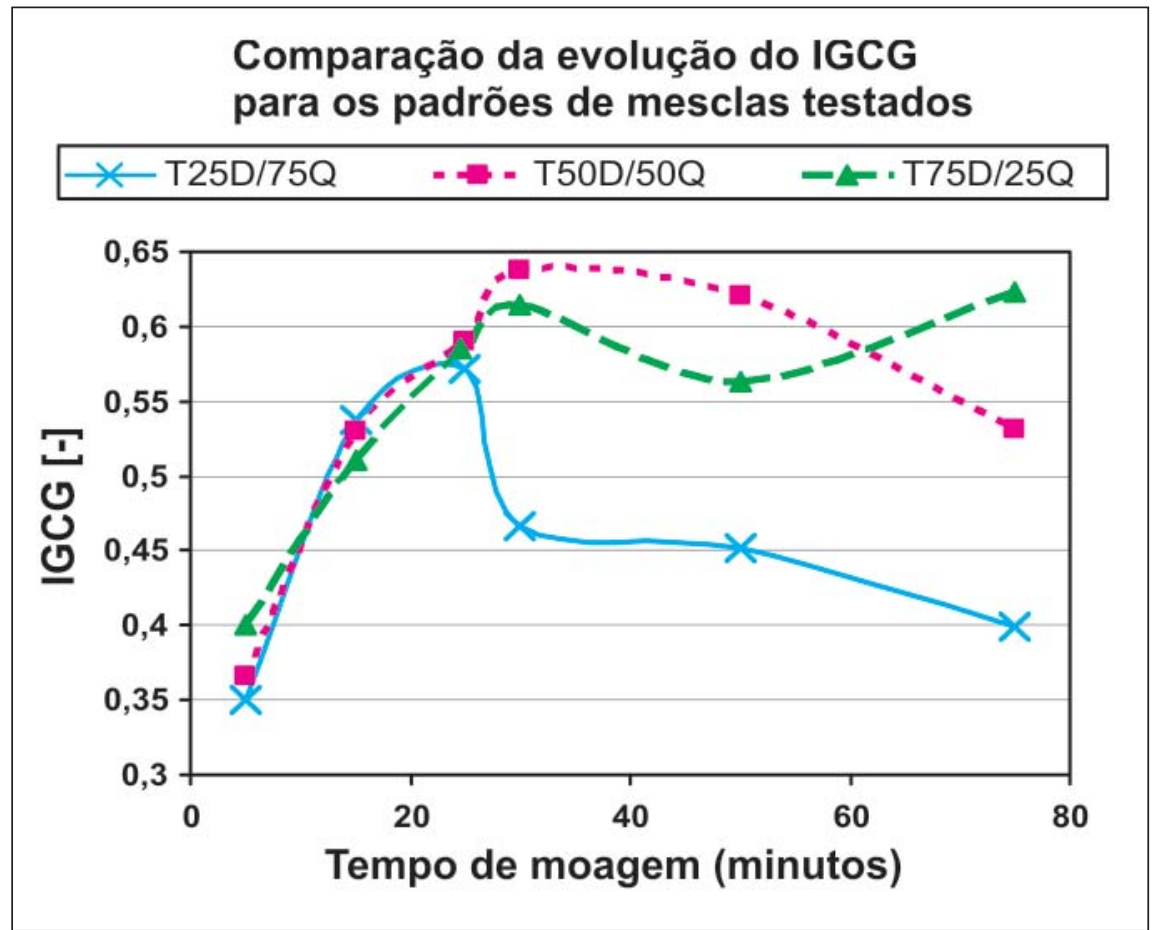

Figura 5 - Comportamento do IGCG para as mesclas na amplitude de tempo de operação considerada. 
Seletividade na cominuição de mesclas de dolomita e quartzo

DELBONI JR., H. Cominuição. In: FERN-

ANDES, F. R. C. et alii (Ed.). Tendências tecnológicas Brasil 2015: geociências e tecnologia mineral. Rio de Janeiro: CETEM/MCT, 2007. p.103-131.

LUZ, J. A. M. da. Conversibilidade entre distribuições probabilísticas usadas em modelos de hidrociclones. Ouro Preto: REM-Revista Escola de Minas, v. 58, n. 1, p. 89-93, jan. mar. 2005.
ROSA, G. M. Cominuição seletiva de mesclas binárias e sua simulação por redes neurais artificiais. Ouro Preto: UFOP, 2009. 184 p. (Dissertação de Mestrado).

ROSA, G. M., LUZ, J. A. M. da. Cominuição de mesclas binárias de dolomita e quartzo. Revista Escola de Minas, 2009. (Submetido).

SUDÁRIO, F. E., LUZ, J. A. M. da. Cominuição seletiva de misturas binárias. In: BRUM, I. A. et alii (Ed.). In: ENCONTRO NACIONAL DE TRATAMENTO DE MINÉRIOS E METAlURGIA EXTRATIVA, 23. Anais... Gramado - RS, Porto Alegre: UFRGS, 2009. v. 2, p. 247-254.

Artigo recebido em 08/10/2009 e aprovado em 28/01/2010.

\section{Maneiras para divulgar suas pesquisas: \\ - Contar para o colega de sala.}

- Deixar uma cópia na biblioteca de sua Universidade.

\section{Mas a melhor maneira de divulgar suas idéias é publicá-las na REM:}

- Indexada: no Scielo, ISI, Scopus, Ebsco, Geosciences

- Periodicidade Trimestral: sem atraso

- Editores e Conselho Editorial de várias Universidades

- Mais de $\mathbf{4 0 0}$ pesquisadores cadastrados como avaliadores ad hoc

- Financiada pelo CNPq e Fapemig

- Apoiada pela Vale, Gaustec, INOX, Petrobras, Geosol, Votorantim, Georadar, Anglo American, Samarco

- A primeira revista do setor mínero-metalúrgico da América do Sul

- A primeira revista do setor mineral a obter ISO 9001:2008

-A REM faz parte do Programa "Open Access". 